(1)

CrossMark

\title{
A joint ERS/ATS policy statement: what constitutes an adverse health effect of air pollution? An analytical framework
}

\author{
George D. Thurston ${ }^{1}$, Howard Kipen ${ }^{2}$, Isabella Annesi-Maesano ${ }^{3}$, \\ John Balmes ${ }^{4,5}$, Robert D. Brook ${ }^{6}$, Kevin Cromar ${ }^{7}$, Sara De Matteis ${ }^{8}$, \\ Francesco Forastiere ${ }^{9}$, Bertil Forsberg ${ }^{10}$, Mark W. Frampton ${ }^{11}$, \\ Jonathan Grigg ${ }^{12}$, Dick Heederik ${ }^{13}$, Frank J. Kelly ${ }^{14}$, Nino Kuenzli ${ }^{15,16}$, \\ Robert Laumbach ${ }^{2}$, Annette Peters ${ }^{17}$, Sanjay T. Rajagopalan ${ }^{18}$, David Rich ${ }^{19}$, \\ Beate Ritz ${ }^{20}$, Jonathan M. Samet ${ }^{21}$, Thomas Sandstrom ${ }^{11}$, Torben Sigsgaard ${ }^{22}$, \\ Jordi Sunyer ${ }^{23}$ and Bert Brunekreef ${ }^{13,24}$
}

Correspondence: Bert Brunekreef, Institute for Risk Assessment Sciences, Universiteit Utrecht, Julius Center for Health Sciences and Primary Care, University Medical Center Utrecht, PO Box 80178, 3508 TD, Utrecht, The Netherlands. E-mail: b.brunekreefवuu.nl

@ERSpublications

Air pollution has many effects on health; this document provides guidance to judge the adversity of such effects http://ow.ly/T2xx304WTZp

Cite this article as: Thurston GD, Kipen H, Annesi-Maesano I, et al. A joint ERS/ATS policy statement: what constitutes an adverse health effect of air pollution? An analytical framework. Eur Respir J 2017; 49: 1600419 [https://doi.org/10.1183/13993003.00419-2016].

ABSTRACT The American Thoracic Society has previously published statements on what constitutes an adverse effect on health of air pollution in 1985 and 2000. We set out to update and broaden these past statements that focused primarily on effects on the respiratory system. Since then, many studies have documented effects of air pollution on other organ systems, such as on the cardiovascular and central nervous systems. In addition, many new biomarkers of effects have been developed and applied in air pollution studies.

This current report seeks to integrate the latest science into a general framework for interpreting the adversity of the human health effects of air pollution. Rather than trying to provide a catalogue of what is and what is not an adverse effect of air pollution, we propose a set of considerations that can be applied in forming judgments of the adversity of not only currently documented, but also emerging and future effects of air pollution on human health. These considerations are illustrated by the inclusion of examples for different types of health effects of air pollution.

Received: Feb 262016 | Accepted after revision: Sept 052016

This article was endorsed by the European Respiratory Society science council and executive committee in September 2016, and approved by the American Thoracic Society board of directors in October 2016.

Support statement: The task force was funded by the European Respiratory Society and the American Thoracic Society. Funding information for this article has been deposited with the Open Funder Registry.

Conflict of interest: Disclosures can be found alongside this article at erj.ersjournals.com

Copyright CERS 2017 
Affiliations: ${ }^{1}$ Depts of Environmental Medicine and Population Health, New York University School of Medicine, New York, NY, USA. ${ }^{2}$ Environmental and Occupational Health Sciences Institute, School of Public Health, Rutgers University, Piscataway, NJ, USA. ${ }^{3}$ Epidemiology of Allergic and Respiratory Diseases Dept (EPAR), Sorbonne Universités, UPMC Université Paris 06, INSERM, Pierre Louis Institute of Epidemiology and Public Health (IPLESP UMRS 1136), Saint-Antoine Medical School, Paris, France. ${ }^{4}$ Dept of Medicine, University of California, San Francisco, CA, USA. ${ }^{5}$ School of Public Health, University of California, Berkeley, CA, USA. ${ }^{6}$ Dept of Cardiology, University of Michigan, Ann Arbor, MI, USA. ${ }^{7}$ Marron Institute of Urban Management, New York University, New York, NY, USA. ${ }^{8}$ Respiratory Epidemiology, Occupational Medicine and Public Health, National Heart and Lung Institute, Imperial College London, London, UK. ${ }^{9}$ Dept of Epidemiology, Lazio Regional Health Service, Rome, Italy. ${ }^{10}$ Dept of Public Health and Clinical Medicine/ Environmental Medicine, Umeå University, Umeå, Sweden. ${ }^{11}$ Pulmonary and Critical Care, Depts of Medicine and Environmental Medicine, University of Rochester Medical Center, Rochester, NY, USA. ${ }^{12}$ Centre for Genomics and Child Health, Queen Mary University of London, London, UK. ${ }^{13}$ Utrecht University, Institute for Risk Assessment Sciences, Utrecht, The Netherlands. ${ }^{14}$ National Institute for Health Research Health Protection Unit: Health Impact of Environmental Hazards, King's College London, London, UK. ${ }^{15}$ Swiss Tropical and Public Health Institute (Swiss TPH), Basel, Switzerland. ${ }^{16}$ University of Basel, Basel, Switzerland. ${ }^{17}$ Helmholtz Zentrum München, Deutsches Forschungszentrum für Gesundheit und Umwelt Institute of Epidemiology II, Neuherberg, Germany. ${ }^{18}$ University of Maryland School of Medicine, Baltimore, MD, USA. ${ }^{19}$ Depts of Public Health Sciences and Environmental Medicine, University of Rochester Medical Center, Rochester, NY, USA. ${ }^{20}$ Center for Occupational and Environmental Health, Fielding School of Public Health, UCLA, Los Angeles, CA, USA. ${ }^{21}$ Dept of Preventive Medicine, Keck School of Medicine of USC, University of Southern California, Los Angeles, CA, USA. ${ }^{22}$ University of Aarhus, Institute of Public Health, Aarhus, Denmark. ${ }^{23}$ CREAL (Center for Research on Environmental Epidemiology, Barcelona), Pompeu Fabra University, Barcelona, Spain. ${ }^{24}$ Julius Center for Health Sciences and Primary Care, University Medical Center Utrecht, Utrecht, The Netherlands.

\section{Background}

The human health effects of exposure to tropospheric outdoor air pollutants, which include both particulate matter and gaseous contaminants, have gained prominence as a global public health concern. Indeed, the most recent Global Burden of Disease (GBD) report lists outdoor air pollution as a leading cause of death and lost disability-adjusted life years, accounting for an estimated $>3$ million premature deaths per year globally $[1,2]$, as well as similarly large numbers of deaths associated with indoor air pollution exposures (e.g. biomass and coal burning smoke). However, outdoor air pollution exposures and trends are quite disparate in different parts of the globe: the principal community air pollutants monitored for regulatory purposes, including carbon monoxide, nitrogen dioxide $\left(\mathrm{NO}_{2}\right)$, sulfur dioxide, particulate matter (PM) and ozone, have generally (but not universally) shown declining concentrations in the developed nations in recent years, while in the low- and middle-income countries (LMIC) pollutant levels have risen dramatically in some (e.g. China and India) [3], but have declined in others (e.g. Mexico).

The contrasting situations (i.e. improvement versus deterioration of air quality) around the globe present differing challenges to the evaluation of air pollution health effects. In the developed world, a critical question is whether adverse effects occur at lower air pollution concentrations and still warrant further regulation below the current national standards and guidelines of the World Health Organization (WHO). In contrast, in other countries there is uncertainty as to whether the concentration-response functions for adverse health effects estimates (e.g. increased risk of death per $\mu \mathrm{g} \cdot \mathrm{m}^{-3}$ particulate matter with a $50 \%$ cut-off aerodynamic diameter of $2.5 \mu \mathrm{m}$ (PM2.5)) derived in the developed world are directly applicable to the differing pollution mixes and concentrations, as well as the differing demographic compositions (e.g. higher percentages of young people), found in many LMICs. In these developing countries, the existence of a health hazard may also be questioned in the absence of relevant local scientific documentation of associations between air pollution and health.

Whether in the high-income countries or LMICs, the aim of air quality management is to limit or avoid adverse impacts of air pollution on the public's health. Thus, there is a need to identify those effects that are considered "adverse", and to separate them from those effects not considered adverse, thereby focusing control measures on the pollutants causing, and populations experiencing, the most severe health impacts. However, while the United States Clean Air Act (www.gpo.gov/fdsys/pkg/USCODE-2013-title42/html/ USCODE-2013-title42-chap85-subchapI-partA-sec7409.htm) requires that the administrator of the US Environmental Protection Agency (EPA) promulgate, for certain "criteria" pollutants, standards that will be sufficient to protect against adverse effects of the air pollutants on health, the Act is silent on the definition of "adverse effect", leaving flexibility for consideration of new knowledge. In Europe, the preamble of the Air Quality Standards also mentions the word "adverse" without further classification: "Humans can be adversely affected by exposure to air pollutants in outdoor air. In response, the European Union has developed an extensive body of legislation which establishes health based standards and objectives for a number of pollutants in air" (http://ec.europa.eu/environment/air/quality/standards.htm). Thus, guidance as to what the latest science indicates to constitute an adverse effect is essential to developing and implementing the most effective air pollution control policies in all parts of the world [4]. 
The American Thoracic Society (ATS) has previously provided such guidance on the definition of adverse health effects of air pollution, beginning with a statement made in 1985, followed by the most recent 2000 ATS statement, What Constitutes an Adverse Health Effect of Air Pollution [5], both of which focused largely on impacts to the respiratory system. However, since that time, new toxicological, clinical and epidemiological studies have identified significant human health effects of air pollution beyond the respiratory tract, and at lower levels of exposure. New types of data streams and approaches to toxicity assessments have also become relevant, generated by the various emerging "omics" and exposure technologies, as well as newly developed systems approaches to toxicity and exposure assessment [6, 7]. Since 2000, substantial evidence has also accumulated on air pollution and the cardiovascular system. As a result, it is now clear that excess morbidity and mortality related to cardiovascular effects of air pollution occur, in addition to respiratory effects [8]. Additionally, new evidence is accumulating for the occurrence of adverse effects of air pollution on the central nervous system (CNS), reproduction and development, and certain metabolic outcomes, as well as cancer [9]. In this document, the ATS and the European Respiratory Society (ERS) now cooperatively update the ATS 2000 statement to address these new scientific findings.

\section{Methods}

To develop a new statement, we have assembled, from the ERS and ATS membership, a group of clinicians, toxicologists, epidemiologists and public health specialists, encompassing a broad range of expertise in studies of air pollution and health. Working group meetings were held in Brussels (Belgium; March 12-13, 2015), Denver (CO, USA; May 16, 2015) and San Francisco (DA, USA; May 16, 2016). Draft report sections were prepared by subgroups, and then discussed at the meetings and by e-mail under the leadership of GDT, HK and BB. At an early stage it was decided that a systematic review of all literature on air pollution and health would not be provided, but instead appropriate examples would be chosen to illustrate considerations of adversity. This statement, like the 2000 statement, is intended to provide guidance to policymakers, clinicians and public health professionals, as well as others who interpret the scientific evidence on the health effects of air pollution for risk management purposes. Because we now can consider a wider, and still growing, range of biomarkers of exposure and health effects of air pollution, this statement first includes a list of general considerations as to what constitutes an adverse health effect, in order to provide guidance to researchers and policymakers when new health effects markers or health outcome associations might be reported in future. These considerations, as summarised in table 1, are applied within this statement to a number of illustrative examples of effects to help in the general assessment as to whether or not specific outcomes can be considered adverse. It is hoped that this approach allows this statement to be a guidance document that is applicable to future assessments as to whether an effect is adverse or not, analogous to the broad applicability of BRADFORD HiLL's [10] considerations for assessing causality of associations between environment and disease. As such, this statement does not offer strict rules or numerical criteria, but rather proposes considerations to be weighed in setting boundaries between adverse and nonadverse health effects.

The scope of this statement is limited to adverse health effects of direct exposure to outdoor air pollutants. While the committee recognised the wide-ranging and serious secondary and higher order adverse health effects attributable to climate change from rising atmospheric concentrations of greenhouse gases and black carbon, their consideration was not included in this statement. For additional consideration of the effects of climate change, the reader is referred to recent reviews, including those of the Intergovernmental Panel on Climate Change [11] and US National Climate Assessment [12].

TABLE 1 Considerations for assessing adversity of clinical or pathological effects

Consideration

\section{Fatality}

2. Persistence of effect

\section{Population risk}

4. Susceptibility

\section{Medical/functional significance}

\section{Pertinent questions}

Does air pollution exposure lead to an increase of short-term or long-term mortality?

How persistent over time is the effect? (Generally, chronic effects such as the induction of new disease are given greater weight, although short-term exposures may lead to changes that increase risk for triggering acute adverse events, such as myocardial infarction)

Is there a shift in the population risk distribution of an adverse event?

Are the very young, older adults or individuals with pre-existing health conditions or specific genetic characteristics more likely to be affected?

Is there evidence of one or more of the following? 1) severe interference with a normal activity of the affected person or persons; 2) incapacitating illness; 3) permanent injury; 4) progressive dysfunction; 5) reduced quality of life 
All of the task force members submitted conflict of interest disclosures that were vetted and managed in accordance with ATS and ERS policies.

\section{Adverse effects of air pollution on health: elements of an analytic framework Introduction}

In this joint statement, we seek to update past ATS statements discussing what constitutes an adverse health effect of outdoor air pollution [5, 13]. Since 2000, additional useful statements on the topic have been produced [14]. As discussed, we do not attempt to provide an exact definition or fixed list of health impacts that are, or are not, adverse. Instead, we propose a number of generalisable "considerations", with examples, to evaluate whether or not an effect is adverse. We aim to provide guidance for evaluation of effects that may be identified in the future, not just the ones seen "under the lamppost" of today's knowledge. How we evaluate whether the literature supports an assessment of adversity is key to our discussion of guidelines. There cannot be precise numerical criteria, as broad clinical knowledge and scientific judgments, which can change over time, must be factors in determining adversity. The WHO [15] has provided one practical framework, categorising evidence of adversity according to benchmarks. The first is that single, not (yet) verified observations by themselves only indicate a need for further research, while the benchmark of adversity is the availability of clear verified evidence for clinical or pathological change. In between these extremes, to which most of our discussion will apply, are those changes where exposure-response relationships and adversity can be posited and assessed in terms of multiple lines of evidence, despite an absence of overt or clinical disease. The more strongly such changes (including most human "biomarkers") are linked to a clinical condition, a pathological change or a pathway to those changes, and the more multiple biomarkers converge on a mechanistic pathway, the stronger the evidence for an adverse effect.

\section{The global burden of disease}

As a starting scope of adverse health effects, we include effects on any condition that contributes to the global burden of disease, as published in the Lancet GBD issues of December 2012 and September 2015 $[1,2,16]$. In the GBD reports, indoor and outdoor air pollution is already considered to be a significant risk factor for ischaemic heart disease, chronic obstructive pulmonary disease (COPD), lung cancer, stroke and childhood respiratory infections $[1,2,16]$.

The GBD project is an ongoing effort that does not provide a final list of every possible health condition contributing to the burden of disease. Therefore, in addition, the committee considers certain clinically relevant conditions that are not (yet) listed in the GBD, but which have been associated with air pollution exposure (e.g. low birthweight, lowered lung function and biomarkers of cardiovascular risk) to be potentially adverse effects of air pollution.

\section{Effects of air pollution on biomarkers of exposure and disease}

In recent decades, many biomarkers of exposure, susceptibility and disease have been identified and studied epidemiologically in relation to air pollution exposure, and it is important to also consider changes in them as potentially adverse health outcomes [17]. Genetic susceptibility, such as the null variant of GSTM1, can enhance susceptibility to biomarker change associated with air pollution [18], and epigenetic changes are garnering increased attention in air pollution research [19].

Biomarkers have been defined, in a report for the US Food and Drug Administration by the Institute of Medicine (IOM) [20], as follows:

Biomarkers are characteristics that are objectively measured and evaluated as indicators of normal biological processes, pathogenic processes, or pharmacologic responses to an intervention. Cholesterol and blood sugar levels are biomarkers, as are blood pressure, enzyme levels, measurements of tumor size from magnetic resonance imaging (MRI) or computed tomography (CT), and the biochemical and genetic variations observed in age-related macular degeneration... they can help public health professionals to identify and track health outcomes.

While it is recognised that not all biomarkers are in the causal pathway for development of a disease, they can nevertheless be valuable indices of a change in disease status or disease risk. The IOM [20] suggested that the BRADFORD Hill considerations [10] can be used to assess the prognostic value or degree of association between a biomarker and a clinical end-point [21]. Temporality, strength of association, consistency and biological plausibility were recognised to be of particular importance. Of major importance to the present document, the IOM recognised that acceptance and use of biomarkers may be different for clinical risk prediction and treatment in individuals, versus planning and evaluation of public health programmes in populations, as also emphasised by other National Academy of Sciences committees [6, 7]. 
Since the list of biomarkers studied to date [22] is extensive, with new biomarkers constantly being added, we cannot review the detailed evidence for or against adversity for each of these. Rather, in line with previous expert committee reports $[6,7]$ we provide a number of specific factors to evaluate when considering effects of air pollution on human biomarkers, and their potential for associated adverse health outcomes.

The IOM suggested a three-stage framework for the development and validation of biomarkers [20], as follows. 1) Analytical validation: to ensure reliability, reproducibility, sensitivity, and specificity of the measurement of the biomarker; 2) qualification: to confirm a strong association with the clinical outcome of concern; and 3) utilisation: contextual analysis to determine that the biomarker is appropriate for the proposed use.

Of these, stages 2 and 3 seem especially relevant to consideration of biomarkers as metrics of adverse health effects of air pollutants. The concluding section of the 2000 ATS statement establishes a baseline of understanding [5], stating that "the committee cautions that not all changes in biomarkers related to air pollution should be considered as indicative of injury that represents an adverse effect". Therefore, here we include illustrative examples of biomarkers that are most strongly associated with adverse effects in this statement's various sections on each respective organ system.

When multiple biomarkers reflective of a particular pathophysiological pathway (e.g. pulmonary inflammation) have been demonstrated to change together, it is deemed that this gives greater credibility to their individual and joint relevance. For instance, in a study of subacute responses to large governmentally imposed changes in air pollution emissions during the 2008 Beijing Summer Olympics, investigators showed that forced exhaled nitric oxide fraction (a measure of airway inflammation) and multiple exhaled breath condensate measures $(\mathrm{pH}$, nitrite, nitrate, 8-isoprostane and malondialdehyde) all responded in unison to decreases in pollutant concentrations, followed by opposite responses to subsequent increases in pollutant levels $[23,24]$. Such collective coherence (a Bradford Hill causality consideration factor) among various biomarkers strengthens the evidence for a shared pathophysiological process: in this case, oxidative stress and inflammation, which have been associated with various adverse health effects (although health effects as such were not measured in this particular panel study). For example, additional measures in the aforementioned study showed significant changes in nonrespiratory biomarkers of systemic inflammation, coagulation, heart rate and blood pressure, suggesting that changes in these biomarkers were indeed related to air pollution, and that they also collectively indicate that adverse effects occurred on a population level, if supported by evidence that the biomarkers are risk factors for adverse outcomes at the population level [25]. Such collective pathophysiological support need not come from within a single study, but the above study does illustrate how considerations for causality, such as consistency, coherence and biological plausibility can also be incorporated into the assessment of adversity. The importance of all of the above pathways, and their respective markers, underlies much of the growing recognition of the range of cardiovascular, systemic/metabolic and developmental effects of air pollution.

The pollution exposures associated with the Beijing Olympics provide an illustrative example of how biomarkers can show substantial changes when ambient pollution levels change dramatically. Approximate $50 \%$ reductions in ambient pollution attained in Beijing during the 2008 Olympics resulted in 30-60\% reductions in multiple biomarkers of respiratory oxidative and stress and inflammation, and even greater increases when strict pollution controls were relaxed [23]. In these young healthy subjects, individual risk of a clinical event is minimal, but population risk, including that of susceptible subpopulations, such as the elderly, is probably substantial.

\section{Population health effects}

As discussed in the 2000 ATS statement, the effects of air pollution can be viewed in terms of an increment in an individual's risk of disease or injury, or in terms of an additional public health risk incurred by a population [26]. Both perspectives are pertinent: any health risk or change beyond some critical boundary, incurred by an exposed individual, could be deemed adverse, while exposure to air pollution beyond an acceptable degree could also enhance risk for a portion of the population. In the case where the relationship between a risk factor and the disease is deemed causal, the 2000 ATS committee considered (and we concur) that "such a shift in the risk factor distribution, and hence the risk profile of the exposed population should be considered adverse, even in the absence of the immediate occurrence of frank illness". Further, considerations of health equity and environmental justice (e.g. socioeconomically disadvantaged populations being more exposed to air pollutants) are also similarly relevant to an assessment of adversity at the population level, with a similar shift in exposure and risk being of greater adversity to such vulnerable populations. These issues have received increased recognition and research funding from US EPA and National Institutes of Health [27].

The context of application to individuals versus populations may also affect interpretation of the validity of biomarkers as predictors of adverse health effects. This is illustrated by the emergence of biomarkers of 
inflammation as potential indicators of either cardiovascular disease or disease risk. For example, C-reactive protein (CRP) is an independent predictor of cardiovascular risk, and is considered to be the best inflammatory marker available at this time [28]. However, it is not known to be in the causal pathway for cardiovascular disease, and it is not clear if reductions of CRP alone are consistently associated with better clinical outcomes. Thus, the IOM [20] concluded that CRP is not appropriate for use as a surrogate end-point, but may still be useful for population risk prediction.

\section{General considerations for assessing adversity of effects}

Overall, considerations of health outcomes and biomarkers, as indicators of adverse effects, are complex.

Table 1 lists several general factors for consideration of adversity. Table 2 complements table 1 by providing a number of considerations for assessing reliability and adversity of biomarker changes. For example, in the case of pollution in Beijing during the Olympics, considerations 1, 2, 3, 4 and 5 in table 2 are all met to a greater or lesser degree for most of the studied biomarkers which showed hypothesised changes, with consideration 6 of requiring analysis of further data.

\section{Assessment of adversity by biological system}

Here we discuss the evidence for adverse health effects of air pollution, considering several organs and outcomes. Figure 1 presents the committee's assessment of established air pollution adverse effects, as well as noting those for which evidence of an association with air pollution and/or adversity is emerging. Outcomes noted in bold in figure 1 are those presently included in the GBD estimates of the health effects of air pollution.

A further issue in the consideration of toxicity or adversity is the rapid development of new methods for toxicity testing and risk assessment [29], as addressed by the IOM in 2007. Here, animal models of toxicity are being replaced by new in vitro approaches to define toxicity, many of which can be seen as analogues of webs of mechanistically informed biomarkers, often relying on "omics" approaches [30]. Detailed consideration of these methods are beyond the scope of this review, but they should be considered further as these innovative approaches are validated in future studies.

\section{Respiratory effects}

The respiratory tract is the primary portal of entry for air pollutants; consequently the respiratory effects of pollutants have been studied for decades. In the $>15$ years since publication of the prior ATS version of this document, much progress has been made in understanding the pathogenic processes and pathophysiology involved in chronic respiratory diseases. For example, both asthma and COPD, as well as other lung diseases, involve airway inflammation, airway remodelling, changes in airway responsiveness, reduced airway clearance and impaired host defence against infection. It is reasonable to posit that air pollution effects on any of these processes may contribute to the underlying disease itself, and examples of such candidate effect biomarkers are provided later.

Effects of air pollution on the onset and/or clinical course of any of the respiratory clinical conditions assessed in the GBD are considered here to constitute adverse effects, as are effects on quality of life. The 2000 ATS document provided a list of respiratory health effects that included adverse clinical outcomes, symptoms and diseases, most of which are now included in the GBD disease list. Similarly, table 3 provides examples of common respiratory conditions and outcomes that have been associated with air pollution exposure. This list is illustrative, and not intended to be exhaustive.

There is convincing epidemiological evidence that both short-term and long-term exposures to air pollutants, including PM, ozone, black carbon and nitrogen oxides are associated with increases in respiratory mortality $[32,33]$. PM exposure also increases the risk of lung cancer [34-36]. Clearly, the

\section{TABLE 2 Considerations for assessing validity and adversity of biomarker changes}

1. Analytical validation

2. Relevance to a clinical condition

3. Appropriateness for proposed use: population versus individual characterisation

4. Presence of multiple converging biomarkers

5. Degree of adherence to Bradford Hill considerations for judging a causal link to air pollution (especially dose/response, replication, biological plausibility and cessation of exposure)

6. Adversity considerations as in table 1 (including adversity of associated clinical end-points) 
FIGURE 1 Overview of diseases, conditions and biomarkers affected by outdoor air pollution. Updated based on [31]. Bold type indicates conditions currently included in the Global Burden of Disease categories.

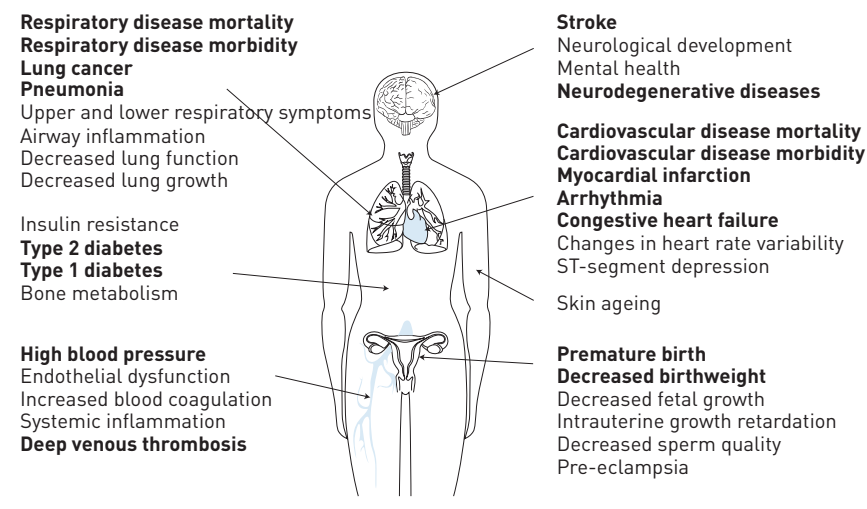

increased mortality associated with higher exposure to air pollution is considered adverse; this is the first and foremost consideration mentioned in table 1.

It is also well established that increased exposures to various air pollutants contribute to exacerbations in patients with chronic respiratory disease, such as asthma, COPD and cystic fibrosis [37]. Exposure to traffic-related air pollution (TRAP) has been associated with worsening of asthma and wheezing [38]. A review of the evidence by the US-based Health Effects Institute [39] found that "sufficient" evidence existed to conclude that TRAP causes respiratory symptoms and exacerbations in children with asthma. However, evidence that TRAP actually causes asthma in children or COPD/asthma in adults was considered insufficient [40, 41]. Another, more recent review found additional evidence for a link between TRAP and incidence of asthma [42].

Long-term improvements in air quality are associated with clinically significant positive effects on lung function growth in children [43]. There is also increasing evidence of associations between increased long-term exposure to TRAP and lung function decline in adults [44], as well as attenuation of this decline with reductions in air pollution [45]. For example, an increased rate of long-term decline in lung function in adults, or a decrease in lung function growth in children, are considered adverse, as these would be deemed "progressive dysfunction", in the terms of table 1.

The previous ATS statement addressed the important question of whether small, transient reductions in lung function, as can be seen in susceptible subjects following acute exposure to ozone, should be considered adverse. The document concluded that small transient changes in forced expiratory volume in $\left.1 \mathrm{~s}(\mathrm{FEV})_{1}\right)$ alone were not necessarily adverse in healthy individuals, but should be considered adverse when accompanied by symptoms. We support the conclusion that, in otherwise healthy individuals, "a small, transient loss of lung function, by itself, should not automatically be designated as adverse" [46]. However, such small lung function changes should be considered adverse in individuals with extant compromised function, such as that resulting from asthma, even without accompanying respiratory symptoms.

Moreover, in considering the magnitude of change and clinical significance, there must also be a distinction made between population changes and individual changes in lung function measures. As discussed in the previous ATS statement, a small but statistically significant mean reduction in FEV1 in a population means that some people had larger reductions, with the likelihood that reductions in a subset of susceptible subjects can have passed a threshold for clinical importance. For example, re-analysis of data from a study by ADAms [47, 48], involving 30 subjects exposed to $0.06 \mathrm{ppm}$ ozone for $6.6 \mathrm{~h}$, showed a $\sim 3 \%$

\section{TABLE 3 Examples of respiratory clinical effects associated with air pollution}

\section{Increased respiratory mortality}

Increased incidence of malignancies of the respiratory tract

Increased incidence, prevalence or frequency of exacerbations in chronic pulmonary disease: asthma, COPD and cystic fibrosis Increased incidence or severity of upper and lower respiratory tract infections

Increased respiratory symptoms that affect quality of life: cough, phlegm, wheezing, dyspnoea and nasal drainage

Increased incidence of preterm birth, low birthweight or growth restriction leading to adverse respiratory outcomes

Reduced growth of lung function in children

Transient (hours) reductions in lung function associated with symptoms in healthy individuals

Transient (hours) reductions in lung function without symptoms in especially susceptible individuals (e.g. children with severe asthma)

Persistent or chronic (weeks, months or years) reductions in lung function 
mean decrease in FEV1. However, two of the subjects had declines in FEV1 >10\% [49]. The more recent literature on long-term effects of air pollution on lung function decline in adults provides further examples on the complexities of defining "adverse effects" for individuals, because effects may depend on a variety of susceptibility factors such as genetic make-up, medication, diet, physical activity or varying metabolic states as seen in diabetics or the obese [50-52].

Given the marked expansion of biomarkers of respiratory disease and pathobiology since the 2000 ATS statement, there is a need to consider the interpretation of changes in biomarkers as potentially adverse, even in the absence of measurable clinical effects. Table 4 provides examples of biomarkers of respiratory health or function that have been used in studies of the respiratory effects of air pollution.

Similar to the considerations for measures of lung function, a small transient change in one of these biomarkers by itself may not be adverse in otherwise healthy individuals. However, such a biomarker change should be considered adverse when additional evidence provides a context for clinical adversity, including changes in complementary biomarkers (as enumerated earlier for the Beijing Olympics study), as well as associations with respiratory symptoms or adverse health outcomes in people with respiratory disease or associations with any adverse effect of air pollution. For example, a small increase in leukocytes in induced sputum following ozone exposure that resolves in $<48 \mathrm{~h}$ may not, by itself, be considered adverse. Yet when such evidence for transient airway inflammation is considered in the context of acute decrements of lung function and/or increases in respiratory symptoms, as well as increased risk of exacerbations in people with respiratory disease, this may constitute evidence of adversity (see considerations 2, 4 and 6 in table 2).

Some pollutant exposures have been shown to transiently increase airways responsiveness [53, 54]. Is this adverse if there are no symptoms or other clinical effects? Airways hyperresponsiveness (AHR) to a specific allergen or a nonspecific challenge (such as methacholine, mannitol or cold air) is an almost universal finding in asthma. AHR gets worse during asthma exacerbations, and improves with treatment. There is evidence that recurrent episodes of bronchoconstriction in people with asthma promote airways remodelling [55], which may lead to irreversible airways obstruction. Based on the applicability of considerations 2-5 in table 1 , we conclude that clinically relevant increases in AHR in asthmatics following pollutant exposure may appropriately be considered adverse, even without accompanying symptoms or other clinical effects.

AHR is frequently found in healthy people without airways disease. Such individuals have an increased risk for reduced lung function and the development of asthma [56]. Worsening of AHR by air pollution in this group may be deemed adverse, especially if persistent or accompanied by symptoms. However, it is less clear, based on the considerations listed in table 1 whether transient increases in airways responsiveness alone are adverse in healthy people with normal airways responsiveness at baseline. Similar to the considerations for FEV1, as discussed earlier, we propose that small, transient changes in airways responsiveness following air pollution exposure in healthy people, without symptoms or clinical illness, are not always adverse. However, small mean population changes can encompass larger effects in some individuals as was the case for FEV1. If the magnitude of the airways responsiveness increase is sufficient for a subject with previously normal airways responsiveness to cross the threshold of AHR (e.g. provocative concentration causing a $20 \%$ fall in $\mathrm{FEV} 1<8 \mathrm{mg} \cdot \mathrm{mL}^{-1}$ ), adversity is evidenced, even in the absence of symptoms [57]. Thus, although this effect is not necessarily adverse in healthy individuals, it may be deemed an adverse population-based risk, as it will probably include susceptible individuals.

\section{Early effects on the respiratory system}

Effects of air pollution on lung function in the first weeks of life, including respiratory rate and tidal breathing flows have been reported [58] and are of concern, since poor neonatal airway function is a risk factor for airflow obstruction in young adults [59]. Subtle changes in infant lung function associated with

\section{TABLE 4 Examples of biomarkers of potentially adverse respiratory health effects}

Increased levels of markers of airway inflammation (e.g. PMNs or inflammatory cytokines in BAL or sputum)

Increased levels of markers of airway injury or inflammation in exhaled breath le.g. increased acidity of exhaled breath condensate or increased FeNO in asthmatics)

Increased levels of blood markers of lung injury (e.g. 8-isoprostanes, club cell secretory protein)

Imaging evidence for lung injury or reduced lung volume

Reduced pulmonary gas exchange (e.g. $D\left\llcorner\mathrm{CO}, D\left\llcorner\mathrm{LN}, P_{\mathrm{aO}}\right.\right.$, pulse oximetry)

Increased airways responsiveness to nonspecific challenge

Increased airways hyperresponsiveness in asthmatic patients

PMN: polymorphonuclear leukocyte; BAL: bronchoalveolar lavage; FeNO: exhaled nitric oxide fraction; DLco: diffusing capacity of the lung for carbon monoxide; $\mathrm{DLNO}$ : diffusing capacity of the lung for nitric oxide; $\mathrm{PaO}_{2}$ : arterial oxygen tension. 
maternal exposure to air pollution are putative biomarkers for long-term consequences of maternal exposure on children's lung function. Additionally, evidence for long-term effects of intrauterine and early postnatal exposure on lung function at 4.5 years of age has been reported [60]. If this association is substantiated by further studies, we consider long-term reduced lung function to be an adverse effect of exposure to air pollution in early life.

\section{Cardiovascular effects}

Since the previous ATS statement, numerous studies have examined associations between acute and chronic exposures to outdoor air pollutants and acute cardiovascular events, as well as biomarkers of relevant cardiovascular pathogenetic mechanisms $[8,61]$. Here we provide examples of how to apply the analytic framework described above for both acute and chronic pollutant/cardiovascular event associations and acute and chronic pollutant/biomarker associations. These examples should not be interpreted as providing arguments for or against causal effects on each outcome, but are the committee's interpretations of the literature, providing a demonstration of how this statement's framework regarding adversity of effects can be applied. Table 5 provides examples of common cardiovascular conditions that have been linked with air pollution in studies, as discussed later.

\section{Myocardial infarction}

Multiple studies have reported acute triggering of myocardial infarction associated with increased pollutant concentrations in the previous few days/hours [62, 63]. Although a meta-analysis using data from 22 European cohort studies reported no clear association between deaths from cardiovascular diseases and long-term concentrations of several PM metrics [64], many other studies have reported associations between long-term averages of air pollutant concentrations and increased cardiovascular mortality and morbidity [65-72] or increased risks of coronary heart disease or coronary events $[66,73,74]$. As an example, in a study of 11 European cohorts, the risk of coronary events was increased by $13 \%$ for each $5 \mu \mathrm{g} \cdot \mathrm{m}^{-3}$ increase in PM2.5. In all those exposed, the attributable fraction is calculated as the relative risk (RR) minus 1 divided by the $R R$, so $0.13 / 1.13=0.12$. On a population basis, this implies that $12 \%$ of coronary events could be prevented by reducing PM2.5 population exposure by $5 \mu \mathrm{g} \cdot \mathrm{m}^{-3}$. Thus, acute fatal and/or nonfatal myocardial infarction represents an adverse effect of air pollution on both the acute and chronic timescales of exposures, as per considerations 1 (fatality) and 5 (medical/functional significance) in table 1 .

\section{Heart failure and stroke}

Both heart failure exacerbations and mortality and stroke have been associated with exposure to air pollution levels experienced over the prior few days, as documented in systematic reviews and meta-analyses [75, 76]. While longer-term exposures have been associated with an increased risk of stroke, few studies have evaluated the risks of heart failure. Thus, such increased risks of heart failure and stroke (particularly of ischaemic aetiology) can be defined as adverse effects of air pollution on an acute timescale. While the risk of stroke can probably be considered an adverse event due to long-term exposures, the risk of heart failure has not yet been conclusively investigated in this regard.

\section{Arrhythmia}

While some studies have reported increased risks of ventricular and atrial arrhythmias associated with outdoor air pollutant levels over the previous few hours and days, the findings are not consistent [77-81]. Should future studies corroborate the indications that air pollution may prompt cardiac arrhythmias, such events would be considered adverse.

High blood pressure

High blood pressure is the leading risk factor for morbidity and mortality worldwide, accounting for nearly half of all myocardial infarctions and strokes [1, 82]. It is listed in the GBD risk assessment [1, 83, 84]. Mounting epidemiological and mechanistic evidence from human and animal studies demonstrates that air

\section{TABLE 5 Cardiovascular clinical effects associated with air pollution}

Cardiovascular disease mortality

Myocardial infarction

Stroke

Increased blood pressure

Arrhythmias

Hospital admissions for congestive heart failure 
pollution is an additional environmental factor capable of increasing blood pressure [85-87]. The ensuing health consequences are demonstrated by a recent meta-analysis whereby short-term increases in outdoor PM2.5 trigger an elevation in blood pressure (1-2 mmHg per $\left.10 \mu \mathrm{g} \cdot \mathrm{m}^{-3}\right)$ over a 5 -day period, while longer-term exposures in the order of 30 days to 1 year prompt even larger pro-hypertensive responses (5$10 \mathrm{mmHg}$ ) [86]. Perhaps most importantly, a growing number of studies further demonstrate that living in regions with higher levels of PM2.5 may also promote the genesis of the chronic hypertensive disease state per se [86, 87]. While some studies indeed support this pathway, firm conclusions cannot be established, given the relative paucity of published evidence on this end-point. Given the well-established linkages between higher blood pressure and the long-term risk of multiple cardiovascular events, chronically increased blood pressure induced by air pollution can itself be considered adverse, while the adversity of more transient increases are less clear, and qualify as a concern that will benefit from further research.

Atherosclerosis is the primary long-term disease mechanism leading to myocardial infarction and stroke [61]. A change in a single biomarker of vascular dysfunction, potentially leading to reduced blood flow may or may not be relevant to a specific ultimate vascular adverse event. However, as discussed above, the effects of air pollution on biomarkers are considered more adverse when such effects occur in a suite of related pathophysiological biomarkers that, together, increase the risk of the clinical outcomes listed in table 5. Such a possible chain of biomarker changes can be seen for many of the biomarkers listed in table 6. For example, substantial progression of arterial calcification indicates progression of atherosclerosis and increased risk for ischaemic events. Experimental studies in humans have indicated that a collection of related pathophysiological biomarkers may be adversely affected by air pollution exposures (e.g. increased arterial stiffness, reduced bioavailability of vascular nitric oxide, reduction of flow-mediated and endothelial-dependent vasodilatation, reduced fibrinolytic capacity/tissue plasminogen activator release, increased thrombocyte adhesiveness, increased ex vivo thrombogenicity and ECG ST-T segment depression).

We now discuss in more detail some of the cardiovascular biomarkers for which there is specific evidence of an association with air pollution.

\section{Heart rate variability}

Heart rate and heart rate variability (HRV) are regulated, in part by the parasympathetic and sympathetic nervous systems. Decreased HRV has been associated with cardiovascular mortality and morbidity in older populations and those at higher risk of cardiovascular events $[8,88]$. While acute changes in HRV over hours to days have convincingly been linked to air pollution exposures [88], the relevance to health is uncertain. It may be postulated that the change in this biomarker reflects an underlying autonomic imbalance that could play a role in triggering clinically significant arrhythmias and other acute cardiovascular events; however, this remains speculative at present. The linkages between changes in HRV and a worsened prognosis have generally been documented in association with presumed chronic reductions in HRV. However, associations between long-term exposure and chronic markers of autonomic function has been a research subject in only a few studies, which indicate possibly complex interactions between long-term exposure to air pollution, HRV and individual susceptibility factors [89-91]. Thus, it is uncertain at this time whether alterations in individual HRV metrics after short-term or long-term exposure can themselves be considered adverse biomarkers or effects of air pollution.

\section{Carotid intima-media thickness}

Carotid intima-media thickness (CIMT), measured using ultrasound, is an established marker of atherogenesis. Since its first use [92], several cross-sectional studies have reported associations between

\section{TABLE 6 Illustrative examples of biomarkers of cardiovascular effects}

Decreased heart rate variability

Changes in ECG depolarisation and repolarisation

Increased carotid intima-media thickness

Increased coronary artery calcification

Carotid artery stenosis

Increased aortic calcification

Increased arterial stiffness

Impaired vascular endothelial function

Impaired vascular fibrinolysis

Increased platelet adhesiveness or activation

Increased thrombogenicity

Increased markers of systemic inflammation, endothelial function, nitric oxide metabolism, oxidation etc. 
home outdoor levels of air pollution and CIMT, including one which combined data from four cohort studies [93]. As summarised in a meta-analysis [94], both the cross-sectional and longitudinal associations between CIMT and air pollution were significant, although the associations between CIMT progression and long-term exposure were based on only three studies. However, another review [95] has not been able to demonstrate a clear association between CIMT progression and incident cardiovascular disease events, and so further work is needed to establish whether an increase in CIMT can be considered an indicator of adverse effects of air pollution on a chronic timescale.

\section{Carotid arterial stenosis}

Carotid artery stenosis (CAS) has been assessed using bilateral carotid artery duplex ultrasound. This important risk factor for cerebrovascular disease and stroke is clearly adverse. A recent study from the USA has indicated that long-term PM2.5 air pollution exposures are independently associated with increased CAS [96].

\section{Vascular function}

Several air pollutants have been associated with impaired microvascular and conduit vascular function in human panel and controlled exposure studies, as well as in animal experiments [97-99]. Chronic endothelial dysfunction is an important biomarker that is both predictive of and causally related to cardiovascular diseases and events [100]. In addition, PM2.5 exposures in the prior few days can impair flow-mediated dilatation of conduit arteries [97]. This probably occurs as a consequence of air pollution-mediated tissue oxidative stress and inflammation, reducing bioavailability of NO while potentiating vasoconstrictive mediators (e.g. endothelin) and pathways [99]. The independent associations between endothelial dysfunction and heightened cardiovascular risk are all in the chronic timescale, and assume that a persistent impairment in vascular health is ongoing, which would indicate adversity as specified by consideration 5 (medical/functional significance) in table 1 and consideration 2 (relevance to a clinical condition) in table 2. In this regard, evidence supports the position that long-term air pollution exposures over months to years are linked to a chronic impairment in vascular endothelial function [97]. Chronic endothelial and vascular dysfunction is judged to be a biomarker of adverse air pollution effects on health. The health relevance of acute reductions in endothelial function induced by air pollution is less certain.

\section{Other biomarkers}

Numerous other biomarkers, intermediate health end-points and pathophysiological changes associated with heightened cardiovascular risk have been investigated in relation to air pollution exposures [8]. A short list of examples is provided in table 6, as a comprehensive list is beyond the scope and focus of this statement. Further to that which has already been noted, changes in markers of inflammation (e.g. high-sensitivity CRP, interleukin-6 and tumour necrosis factor- $\alpha$ ), coagulation (e.g. prothrombin time, fibrinogen and ex vivo thrombus formation time), thrombosis (e.g. CD40L, p-selectin and platelet activation metrics), adipocytokines (e.g. leptin and adiponectin), endothelial activation, haemodynamic markers (e.g. Von Willebrand factor, endothelin and nitrite) and lipid oxidation (low-density lipoprotein oxidation status and high-density lipoprotein dysfunction) have been noted. In addition to blood-based biomarkers, markers of heightened arrhythmia potential (e.g. repolarisation abnormalities), and myocardial ischaemia (ST depression) have been associated with air pollution exposure in human studies. Many of these end-points are indeed linked to a greater cardiovascular risk in the long run. However, most of the associations with air pollution have only been shown to occur over short timescales of exposures, i.e. in the order of days. Assessing changes in multiple biomarkers, as discussed earlier, may strengthen the case for adversity. While it is possible that acute or transient perturbations in these biomarkers might play a role in triggering an acute event, no firm conclusion can be made at this time to determine that these other acute biomarker changes individually constitute adverse health effects.

\section{Emerging adverse effects of outdoor air pollution}

The assessment of adverse health effects of outdoor air pollution initially focused on respiratory health outcomes, and, more recently, cardiovascular outcomes. However, associations have also been reported between outdoor air pollution and systemic or metabolic effects, involving multiple pathophysiological pathways. These have included systemic inflammation, oxidative stress, immune modulation and epigenetic alteration. This suggests that multiple health outcomes, not necessarily detectable by short-term studies (e.g. daily time series), may also be relevant.

\section{Diabetes and obesity}

There is an emerging body of evidence linking outdoor air pollution to type 2 diabetes, as suggested by a recent systematic review and meta-analysis [101]. This review specifically indicated that the observed associations were stronger among females than males. These findings are well supported by animal experiments, which have indicated that systemic inflammation, immune responses in adipose tissue and 
peripheral insulin resistance can be induced by exposure to particulate matter [102]. This evidence is further supported by reports of insulin resistance and elevated haemoglobin A1c concentrations associated with air pollution $[103,104]$. Epidemiological studies of short-term exposure to outdoor air pollution have indicated changes in systemic inflammation markers in individuals with diabetes or impaired glucose tolerance. A few prospective cohort studies have also suggested that environmental pollutants contribute to the development of childhood obesity [105], and a variety of mechanisms that may contribute to obesity and enhanced insulin resistance have been demonstrated. These possible mechanisms include glucose and lipid dysregulation in tissues such as adipose and hepatic tissue and skeletal muscle and brown adipose through pathways well known to be altered in insulin resistance [105]. In line with this observation, associations between air pollution exposures at the place of residence and liver enzymes have also been observed [106]. Immunomodulatory effects of outdoor air pollution are further hypothesised to promote an earlier onset of type 1 diabetes [107, 108]. Clearly, development of these systemic/metabolic outcomes would be considered adverse, as per consideration 2 (persistence) in table 1; however, their associations with air pollution are not sufficiently robust at this time to consider them to be adverse effects of air pollution.

\section{Epigenetic alterations}

Emerging evidence suggests that outdoor air pollution alters the epigenetic regulation of white blood cells and other tissues, potentially resulting in transient, as well as permanent changes in gene regulation in various tissues [109]. Such epigenetic changes suggest a mechanism for understanding the links between outdoor air pollution exposure and impaired function of multiple organs. Furthermore, changes in micro-RNA and other RNA species may constitute important signalling pathways, orchestrating an interplay between different organs that may indicate impairment by outdoor air pollution exposures. Clear evidence of adversity is still evolving.

\section{Pregnancy and developmental outcomes}

The 2000 ATS statement identified infants as a susceptible group, but did not directly address the question of adverse effects of in utero exposures. In this section, we consider the emerging evidence that maternal exposure to air pollution results in a wide range of adverse effects that may resolve after birth or continue or increase susceptibility to disease in later life [110,111].

\section{Birthweight and prematurity}

A number of epidemiological studies report associations between maternal exposure to air pollution and newborn infant outcomes. Among these are reductions in overall birthweight, low birthweight $(<2500 \mathrm{~g}$ at any gestational age), low birthweight at term $(<2500 \mathrm{~g}$ at $\geqslant 37$ weeks gestation) and preterm birth ( $<37$ weeks gestation). Preterm birth and low birthweight are well-known for their association with neonatal morbidity and mortality and have also been associated with adult morbidity [112-114]. A systematic review and meta-analysis published in 2012 reported reduced birthweight and increased risk for low birthweight associated with exposure to $\mathrm{NO}_{2}, \mathrm{PM}_{10}$ and $\mathrm{PM} 2.5$ for entire-pregnancy exposures [115]. The meta-analysis also reported positive associations between air pollutant exposures and increased risk of preterm birth. Following this review, two recent multicohort studies have focused on the association between maternal exposure and "low birthweight at term", because infants in this weight category are considered to have suffered fetal growth restrictions. One of these studies [116] estimated that $11 \%$ of term low birthweight cases would be avoided were PM2.5 concentrations reduced by $5 \mu \mathrm{g} \cdot \mathrm{m}^{-3}$. Low birthweight at term is known to be associated with increased risk of neonatal death and has been associated with other adverse outcomes [116-121]. In addition, two so-called "natural experiments" found community-level air pollution interventions to reduce pollution and affect preterm birth or birthweight [122, 123]. Results from these studies and meta-analysis indicate that maternal exposure to air pollution is associated with increased risk of low birthweight, but there was considerable variability in risk estimates by specific gestational period. We conclude that low birthweight at term and prematurity are adverse effects, when caused by maternal air pollution exposure, in view of the shifts in population risk for later adverse medical conditions associated with low birthweight (consideration 3 in table 1).

\section{Stillbirth}

Stillbirth has been associated with maternal exposure to $\mathrm{PM}$ and $\mathrm{NO}_{2}$ [124-127]; however, not all studies agree [127]. Stillbirth is clearly an adverse outcome (consideration 1 in table 1), but its association with air pollution is still not sufficiently proven.

\section{Congenital abnormalities}

A study completed in the San Joaquin Valley (CA, USA) reported that the highest quartile of maternal $\mathrm{NO}_{2}$ exposure was associated with neural tube defects [128]. However, evidence for an association between air pollution and congenital abnormalities has been inconsistent to date $[129,130]$. Congenital 
abnormality is clearly an adverse outcome in terms of both persistence and medical significance, but its association with air pollution exposure is still uncertain.

\section{Neurological and psychiatric outcomes}

Substantial evidence points to a potential role for air pollution in diseases of the CNS [131-133] and psychiatric disorders [134] (table 7). Biological mechanisms underlying these possible pollution effects are presently not well understood, and relevant epidemiological investigations are still at an early stage. Cognitive function and psychiatric conditions were discussed upon briefly under the heading of "quality of life" in the 2000 statement, but are substantially expanded upon in this statement.

\section{Neurodegenerative disorders}

Dementia is a general term for loss of memory and other mental abilities severe enough to interfere with daily life. Alzheimer's disease and vascular dementia, previously known as multi-infarct or post-stroke dementia, are the most common forms of dementia. Higher estimated annual exposure to PM2.5 has been associated with worse performance in cognitive function tests, in particular tests evaluating episodic memory [135]. An increased rate of decline in cognitive function may also be associated with higher air pollution exposures [136]. Some studies have reported associations between exposure to air pollutants and dementia [137, 138], but not all study results support such a relationship [139].

Several pathways leading from inhalation of air pollutants to adverse effects in the CNS have been postulated: direct transport via the olfactory epithelium, traversing metabolic barriers in the olfactory epithelium, systemic transport via the blood-brain barrier and sensory afferent signalling from the gastrointestinal tract [132]. Evidence of changes in innate immune response, disruption of synaptic function and neuroinflammation has been observed in response to air pollution [140, 141]. Alternatively, adverse CNS health effects from air pollution may be secondary to systemic impacts mediated by other body systems. Subclinical and clinical cardiovascular and metabolic disease are established risk factors for cognitive decline and dementia [142], and it is likely that at least part of the observed impact of air pollutants on cognitive disease risk occurs as a result of air pollution-induced ischaemic effects. Whether mediated by systemic disease or due to the direct impact of air pollution on the CNS, neurodegenerative disease outcomes are clearly adverse.

\section{Neurodevelopment and behavioural disorders in children}

Pioneering studies of exposure to lead have clearly documented effects on children's neurodevelopment, with end-points such as increased hyperactivity, reduced attention and several cognitive deficits [143]. Maternal or child exposure to air pollutants during pregnancy, infancy or childhood (when the brain neocortex develops rapidly) has been related to delays in cognitive development in children [144-148]. Recent studies have evaluated the association between prenatal and perinatal exposures to air pollutants and childhood behavioural disorders, but with conflicting results [149-151]. Impaired neurodevelopment in childhood is clearly adverse.

\section{Psychiatric disorders}

It has been postulated that air pollution induced oxidative stress can be related to dopaminergic neurotoxicity, and therefore to depressive moods. The association between exposure to outdoor air pollution and depressive symptoms has been evaluated, with mixed results [1, 152]. Other studies on the mental health effects of air pollution suggest a link between short-term variability in air pollution and suicide [153], although confounding from meteorological conditions, including rainfall and visibility, could not be excluded. POWER et al. [154] reported an exposure-dependent association between higher levels of PM2.5 and anxiety, especially

TABLE 7 Neurological and psychiatric conditions tentatively associated with air pollution and examples of markers of neurological effects

\section{Conditions}

Markers
Alzheimer's disease and other dementias

Parkinson's disease

Reduced cognitive function in adults

Delayed neurodevelopment in children

Depression

Anxiety disorders

Structural brain damage at functional magnetic resonance imaging

Neurobehavioral testing

Cognitive function testing 
in the month immediately preceding the scoring of anxiety. Depression and anxiety disorders are clearly adverse conditions.

\section{Imaging and biomarker studies}

Advances in functional imaging, such as functional MRI and positron emission tomography scanning, have begun to be applied to air pollution health studies. A study of brain imaging and function in pre-adolescence showed structural brain damage related to pulmonary arterial hypertension exposure in utero [155]. Using MRI among those aged $\geqslant 60$ years, WILKER et al. [156] have examined the associations between residential long-term exposure to outdoor air pollution and markers of brain ageing, free from dementia and stroke. Exposure to elevated levels of PM2.5 was statistically associated with smaller total cerebral brain volume and with higher odds of covert brain infarcts, indicating that air pollution is associated with evidence of structural brain ageing. Such structural brain ageing changes would clearly constitute an adverse effect, because of their relevance to clinical conditions (consideration 2 in table 2), but specific pollution-associated abnormalities have yet to be identified.

\section{Cognitive impacts}

This committee has concluded that any detectable level of transient or permanent loss of cognitive function, measured by a validated test, should be considered adverse. Thus, decrements in cognitive function are treated differently to decrements in respiratory function, for which the committee concluded that, in otherwise healthy individuals, "a small, transient loss of lung function, by itself, should not automatically be designated as adverse". Subtle, but important, deficits in cognition or other neurobehavioral functions may be asymptomatic, and repeated episodes of transient cognitive deficits, even if completely reversible, could have cumulative effects on educational attainment and achievement. Under a broad definition of health, the committee determined that a decrement in educational achievement due to air pollution exposure would be considered an adverse health effect. The committee was also in agreement that any detectable permanent decrement in cognitive function attributable to air pollution should be considered an adverse health effect.

\section{Discussion and conclusions}

The authors of this statement have recognised and discussed substantial new areas of human health effects from air pollution, choosing the GBD reports as a starting point for the identification of health effects to be considered adverse when convincingly associated with exposure to air pollution. In addition, we have identified a series of considerations to help define adversity of effects of air pollution on subclinical changes short of disease, and provide illustrative examples of their application. These include alterations in some biomarkers that contribute to the development of clinical disease. Effects on the respiratory system listed in the previous ATS statement are elaborated upon, and newly recognised respiratory effects of exposure to air pollution during pregnancy are detailed. Cardiovascular end-points were especially considered, as an important expansion of the previous ATS statement, in large part because cardiovascular disease is so widespread and increasing around the globe, but also because of the enormous volume of new literature now supporting the adverse effects of air pollution on cardiovascular disease development and exacerbation. Systemic conditions are a new area of concern in which ample evidence for effects of air pollution on biomarkers of systemic effects is available. Wholly new sections on metabolic dysfunction, pregnancy and developmental outcomes, as well as CNS and psychiatric effects, have now been included. It is clear from the vantage point of 2016, more than 15 years since the previous statement, that the list of detectible air pollution health effects and their indices continues to expand, making a determination of the adversity of these numerous effects more and more important.

Future statements should continue to build upon the considerations for adversity presented here, investigating areas such as systemic effects, reproductive effects and CNS effects, while advancing our understanding of the best uses of biomarkers across the wide spectrum of outcomes affected by outdoor air pollution.

\section{References}

1 Lim SS, Vos T, Flaxman AD, et al. A comparative risk assessment of burden of disease and injury attributable to 67 risk factors and risk factor clusters in 21 regions, 1990-2010: a systematic analysis for the Global Burden of Disease Study 2010. Lancet 2012; 380: 2224-2260.

2 Forouzanfar MH, Alexander L, Anderson HR, et al. Global, regional, and national comparative risk assessment of 79 behavioural, environmental and occupational, and metabolic risks or clusters of risks in 188 countries, 1990-2013: a systematic analysis for the Global Burden of Disease Study 2013. Lancet 2015; 386: 2287-2323.

3 Van Donkelaar A, Martin RV, Brauer M, et al. Use of satellite observations for long-term exposure assessment of global concentrations of fine particulate matter. Environ Health Perspect 2015; 123: 135-143.

4 Künzli N, Joss MK, Gintowt E. Global standards for global health in a globalized economy. Int J Public Health 2015; 60: 757-759. 

Care Med 2000; 161: 665-673.

6 National Research Council. Exposure Science in the 21st Century: A Vision and a Strategy. Washington, DC The National Academies Press, 2012.

7 National Research Council. Toxicity Testing in the 21st Century: A Vision and a Strategy. Washington, DC, The National Academies Press, 2007.

8 Brook RD, Rajagopalan S, Pope CA, et al. Particulate matter air pollution and cardiovascular disease: an update to the scientific statement from the American Heart Association. Circulation 2010; 121: 2331-2378.

9 Filippini T, Heck JE, Malagoli C, et al. A review and meta-analysis of outdoor air pollution and risk of childhood leukemia. J Environ Sci Health C Environ Carcinog Ecotoxicol Rev 2015; 33: 36-66.

10 Bradford Hill A. The environment and disease: association or causation? Proc R Soc Med 1965; 58: 295-300

11 Smith KR, Woodward A, Campbell-Lendrum D. Human health: impacts, adaptation, and co-benefits. In: Field CB, Barros VR, Dokken DJ, eds. Climate Change 2014: Impacts, Adaptation, and Vulnerability. Cambridge, Cambridge University Press, 2014; pp. 709-754.

12 Melillo JM, Richmond TC, Yohe GW. Climate Change Impacts in the United States: The Third National Climate Assessment. http://nca2014.globalchange.gov/ Date last updated: 2014.

13 Andrews C, Buist S, Ferris BG Jr. Guidelines as to what constitutes an adverse respiratory health effect, with special reference to epidemiologic studies of air pollution. Am Rev Respir Dis 1985; 131: 666-668.

14 Gouveia NC, Maisonet M. Health effects of air pollution: an overview. In: Air Quality Guidelines Global Update 2005. Copenhagen, World Health Organization Regional Office for Europe, 2006; pp. 87-110.

15 World Health Organization (WHO). Criteria used in establishing guideline values. In: WHO Air Quality Guidelines for Europe. 2nd Edn. Copenhagen, WHO, 2000; pp. 11-31.

16 Burnett RT, Pope CA, Ezzati M, et al. An integrated risk function for estimating the global burden of disease attributable to ambient fine particulate matter exposure. Environ Health Perspect 2014; 122: 397-403.

17 Rom WN, Boushey H, Caplan A. Experimental human exposure to air pollutants is essential to understand adverse health effects. Am J Respir Cell Mol Biol 2013; 49: 691-696.

18 Schwartz J, Park SK, O’Neill MS, et al. Glutathione-S-transferase M1, obesity, statins, and autonomic effects of particles: gene-by-drug-by-environment interaction. Am J Respir Crit Care Med 2005; 172: 1529-1533.

19 Burris $\mathrm{HH}$, Baccarelli AA. Environmental epigenetics: from novelty to scientific discipline. J Appl Toxicol 2014 34: 113-116.

20 Micheel CM, Ball JR. Evaluation of Biomarkers and Surrogate Endpoints in Chronic Disease. Washington, Institute of Medicine of the National Academies, 2010.

21 Schatzkin A, Freedman LS, Schiffman MH, et al. Validation of intermediate end points in cancer research. $J$ Nat Cancer Inst 1990; 82: 1746-1752.

22 Mirowsky J, Gordon T. Noninvasive effects measurements for air pollution human studies: methods, analysis, and implications. J Expo Sci Environ Epidemiol 2015; 25: 354-380.

23 Huang W, Wang GF, Lu SE, et al. Inflammatory and oxidative stress responses of healthy young adults to changes in air quality during the Beijing Olympics. Am J Respir Crit Care 2012; 186: 1150-1159.

24 Gong JC, Zhu T, Kipen H, et al. Malondialdehyde in exhaled breath condensate and urine as a biomarker of air pollution induced oxidative stress. J Expo Sci Environ Epidemiol 2013; 23: 322-327.

25 Rich DQ, Kipen HM, Huang W, et al. Association between changes in air pollution levels during the Beijing Olympics and biomarkers of inflammation and thrombosis in healthy young adults. JAMA 2012; 307: 2068-2078.

26 Rose G. Sick individuals and sick populations. Int J Epidemiol 1985; 14: 32-38.

27 Gochfeld M, Burger J. Disproportionate exposures in environmental justice and other populations: the importance of outliers. Am J Public Health 2011; 101: Suppl. 1, S53-S63.

28 Greenland P, Alpert JS, Beller GA, et al. 2010 ACCF/AHA guideline for assessment of cardiovascular risk in asymptomatic adults: executive summary: a report of the American College of Cardiology Foundation/American Heart Association task force on practice guidelines. Circulation 2010; 122: 2748-2764.

29 Krewski D. Toxicity Testing in the 21st Century: a Vision and a Strategy. Washington, National Research Council of the National Academies, 2007.

30 Hebels DG, Georgiadis P, Keun HC, et al. Performance in omics analyses of blood samples in long-term storage: opportunities for the exploitation of existing biobanks in environmental health research. Environ Health Perspect 2013; 121: 480-487.

31 Rückerl R, Schneider A, Breitner S, et al. Health effects of particulate air pollution: a review of epidemiological evidence. Inhal Toxicol 2011; 23: 555-592.

32 Hoek G, Krishnan RM, Beelen R, et al. Long-term air pollution exposure and cardio-respiratory mortality: a review. Environ Health 2013; 12: 43.

33 Atkinson RW, Kang S, Anderson HR, et al. Epidemiological time series studies of PM2.5 and daily mortality and hospital admissions: a systematic review and meta-analysis. Thorax 2014; 69: 660-665.

34 Pope CA, Burnett RT, Thun MJ, et al. Lung cancer, cardiopulmonary mortality, and long-term exposure to fine particulate air pollution. JAMA 2002; 287: 1132-1141.

35 Raaschou-Nielsen O, Andersen ZJ, Beelen R, et al. Air pollution and lung cancer incidence in 17 European cohorts: prospective analyses from the European Study of Cohorts for Air Pollution Effects (ESCAPE). Lancet Oncol 2013; 14: 813-822.

36 Loomis D, Grosse Y, Lauby-Secretan B, et al. The carcinogenicity of outdoor air pollution. Lancet Oncol 2013; 14: $1262-1263$.

37 Goss $\mathrm{CH}$, Newsom SA, Schildcrout JS, et al. Effect of ambient air pollution on pulmonary exacerbations and lung function in cystic fibrosis. Am J Respir Crit Care Med 2004; 169: 816-821.

38 Lee SM, Frampton MW. Traffic-related urban air pollution. In: Tarlo S, Cullinan P, Nemery B, eds. Occupational and Environmental Lung Diseases: Diseases from Work, Home, Outdoor and Other Exposures. Chichester, John Wiley \& Sons, 2010.

39 Health Effects Institute. Traffic-Related Air Pollution: a Critical Review of the Literature on Emissions, Exposure, and Health Effects. Boston, Health Effects Institute, 2010. 
Schikowski T, Adam M, Marcon A, et al. Association of ambient air pollution with the prevalence and incidence of COPD. Eur Respir J 2014; 44: 614-626.

Song Q, Christiani DC, Wang X, et al. The global contribution of outdoor air pollution to the incidence, prevalence, mortality and hospital admission for chronic obstructive pulmonary disease: a systematic review and meta-analysis. Int J Environ Res Public Health 2014; 11: 11822-11832.

Anderson HR, Favarato G, Atkinson RW. Long-term exposure to air pollution and the incidence of asthma: meta-analysis of cohort studies. Air Qual Atmos Health 2013; 6: 47-56.

Gauderman WJ, Urman R, Avol E, et al. Association of improved air quality with lung development in children. N Engl J Med 2015; 372: 905-913.

Rice MB, Ljungman PL, Wilker EH, et al. Long-term exposure to traffic emissions and fine particulate matter and lung function decline in the Framingham Heart study. Am J Respir Crit Care Med 2015; 191: 656-664.

Downs SH, Schindler C, Liu LJS, et al. Reduced exposure to $\mathrm{PM}_{10}$ and attenuated age-related decline in lung function. N Engl J Med 2007; 357: 2338-2347.

Brouwer AFJ, Roorda RJ, Duiverman EJ, et al. Reference values for peak flow and FEV1 variation in healthy schoolchildren using home spirometry. Eur Respir J 2008; 32: 1262-1268.

Adams WC. Human pulmonary responses with 30 -minute time intervals of exercise and rest when exposed for 8 hours to 0.12 PPM ozone via square-wave and acute triangular profiles. Inhal Toxicol 2006; 18: 413-422.

Adams WC. Comparison of chamber 6.6-h exposures to 0.04-0.08 PPM ozone via square-wave and triangular profiles on pulmonary responses. Inhal Toxicol 2006; 18: 127-136.

Brown JS, Bateson TF, McDonnell WF. Effects of exposure to $0.06 \mathrm{ppm}$ ozone on FEV1 in humans: a secondary analysis of existing data. Environ Health Perspect 2008; 116: 1023-1026.

Schikowski T, Schaffner E, Meier F, et al. Improved air quality and attenuated lung function decline: modification by obesity in the SAPALDIA cohort. Environ Health Perspect 2013; 121: 1034-1039.

Thun GA, Imboden M, Künzli N, et al. Follow-up on genome-wide main effects: do polymorphisms modify the air pollution effect on lung function decline in adults? Environ Int 2014; 64: 110-115.

Imboden M, Kumar A, Curjuric I, et al. Modification of the association between $\mathrm{PM}_{10}$ and lung function decline by cadherin 13 polymorphisms in the SAPALDIA cohort: a genome-wide interaction analysis. Environ Health Perspect 2015; 123: 72-79.

Frampton MW, Morrow PE, Cox C, et al. Effects of nitrogen dioxide exposure on pulmonary function and airway reactivity in normal humans. Am Rev Respir Dis 1991; 143: 522-527.

Brown JS. Nitrogen dioxide exposure and airway responsiveness in individuals with asthma. Inhal Toxicol 2015 27: $1-14$.

Grainge CL, Lau LCK, Ward JA, et al. Effect of Bronchoconstriction on Airway Remodeling in Asthma. N Engl Med 2011; 364: 2006-2015

Postma DS, Boezen HM. Rationale for the Dutch hypothesis. Allergy and airway hyperresponsiveness as genetic factors and their interaction with environment in the development of asthma and COPD. Chest 2004; 126: Suppl. 2, 96S-104S.

Crapo RO, Casaburi R, Coates AL, et al. Guidelines for methacholine and exercise challenge testing - 1999. Am J Respir Crit Care Med 2000; 161: 309-329.

Latzin P, Röösli M, Huss A, et al. Air pollution during pregnancy and lung function in newborns: a birth cohort study. Eur Respir J 2009; 33: 594-603.

Stern G, Latzin P, Thamrin C, et al. How can we measure the impact of pollutants on respiratory function in very young children? Methodological aspects. Paediatr Respir Rev 2007; 8: 299-304.

Morales E, Garcia-Esteban R, de la Cruz OA, et al. Intrauterine and early postnatal exposure to outdoor air pollution and lung function at preschool age. Thorax 2015; 70: 64-73.

Brook RD, Franklin B, Cascio W, et al. Air pollution and cardiovascular disease: a statement for healthcare professionals from the Expert Panel on Population and Prevention Science of the American Heart Association. Circulation 2004; 109: 2655-2671.

Mustafic H, Jabre P, Caussin C, et al. Main air pollutants and myocardial infarction a systematic review and meta-analysis. JAMA 2012; 307: 713-721.

Gardner B, Ling F, Hopke PK, et al. Ambient fine particulate air pollution triggers ST-elevation myocardia infarction, but not non-ST elevation myocardial infarction: a case-crossover study. Part Fibre Toxicol 2014; 11: 1.

Beelen R, Stafoggia M, Raaschou-Nielsen O, et al. Long-term exposure to air pollution and cardiovascular mortality: an analysis of 22 European cohorts. Epidemiology 2014; 25: 368-378.

Tonne C, Wilkinson P. Long-term exposure to air pollution is associated with survival following acute coronary syndrome. Eur Heart J 2013; 34: 1306-1311.

Miller KA, Siscovick DS, Sheppard L, et al. Long-term exposure to air pollution and incidence of cardiovascular events in women.N Engl J Med 2007; 356: 447-458.

Crouse DL, Peters PA, van Donkelaar A, et al. Risk of nonaccidental and cardiovascular mortality in relation to long-term exposure to low concentrations of fine particulate matter: a Canadian national-level cohort study. Environ Health Perspect 2012; 120: 708-714.

Pope CA III, Turner MC, Burnett RT, et al. Relationships between fine particulate air pollution, cardiometabolic disorders, and cardiovascular mortality. Circ Res 2015; 116: 108-115.

Raaschou-Nielsen O, Andersen ZJ, Jensen SS, et al. Traffic air pollution and mortality from cardiovascular disease and all causes: a Danish cohort study. Environ Health 2012; 11: 60.

Atkinson RW, Carey IM, Kent AJ, et al. Long-term exposure to outdoor air pollution and incidence of cardiovascular diseases. Epidemiology 2013; 24: 44-53.

Lipsett MJ, Ostro BD, Reynolds P, et al. Long-term exposure to air pollution and cardiorespiratory disease in the California teachers study cohort. Am J Respir Crit Care Med 2011; 184: 828-835.

Thurston GD, Ahn J, Cromar KR, et al. Ambient particulate matter air pollution exposure and mortality in the NIH-AARP diet and health cohort. Environ Health Perspect 2016; 124: 484-490.

Puett RC, Hart JE, Yanosky JD, et al. chronic fine and coarse particulate exposure, mortality, and coronary heart disease in the Nurses' Health Study. Environ Health Perspect 2009; 117: 1697-1701. 

coronary events: prospective cohort study and meta-analysis in 11 European cohorts from the ESCAPE project. BMJ 2014; 348: f7412.

75 Shah ASV, Langrish JP, Nair H, et al. Global association of air pollution and heart failure: a systematic review and meta-analysis. Lancet 2013; 382: 1039-1048.

76 Shah ASV, Lee KK, McAllister DA, et al. Short term exposure to air pollution and stroke: systematic review and meta-analysis. BMJ 2015; 350: h1295.

77 Link MS, Dockery DW. Air pollution and the triggering of cardiac arrhythmias. Curr Opin Cardiol 2010; 25: $16-22$.

78 Anderson HR, Armstrong B, Hajat S, et al. Air pollution and activation of implantable cardioverter defibrillators in London. Epidemiology 2010; 21: 405-413.

79 Zanobetti A, Coull BA, Gryparis A, et al. Associations between arrhythmia episodes and temporally and spatially resolved black carbon and particulate matter in elderly patients. Occup Environ Med 2014; 71: 201-207.

80 Rich DQ, Mittleman MA, Link MS, et al. Increased risk of paroxysmal atrial fibrillation episodes associated with acute increases in ambient air pollution. Environ Health Perspect 2006; 114: 120-123.

81 Link MS, Luttmann-Gibson H, Schwartz J, et al. Acute exposure to air pollution triggers atrial fibrillation. J Am Coll Cardiol 2013; 62: 816-825.

82 Kearney PM, Whelton M, Reynolds K, et al. Global burden of hypertension: analysis of worldwide data. Lancet 2005; 365: 217-223.

83 Murray CJL, Ezzati M, Flaxman AD, et al. GBD 2010: a multi-investigator collaboration for global comparative descriptive epidemiology. Lancet 2012; 380: 2055-2058.

84 Murray CJL, Ezzati M, Flaxman AD, et al. GBD 2010: design, definitions, and metrics. Lancet 2012; 380: 2063-2066.

85 Brook RD, Rajagopalan S. Particulate matter, air pollution, and blood pressure. J Am Soc Hypertens 2009; 3: $332-350$.

86 Liang R, Zhang B, Zhao X, et al. Effect of exposure to PM2.5 on blood pressure: a systematic review and meta-analysis. J Hypertens 2014; 32: 2130-2141.

87 Chen H, Burnett RT, Kwong JC, et al. Spatial association between ambient fine particulate matter and incident hypertension. Circulation 2014; 129: 562-569.

88 Pieters N, Plusquin M, Cox B, et al. An epidemiological appraisal of the association between heart rate variability and particulate air pollution: a meta-analysis. Heart 2012; 98: 1127-1135.

89 Felber Dietrich D, Gemperli A, Gaspoz JM, et al. Differences in heart rate variability associated with long-term exposure to $\mathrm{NO}_{2}$. Environ Health Perspect 2008; 116: 1357-1361.

90 Adam M, Felber Dietrich D, Schaffner E, et al. Long-term exposure to traffic-related PM 10 and decreased heart rate variability: is the association restricted to subjects taking ACE inhibitors? Environ Int 2012; 48: 9-16.

91 Adam M, Imboden M, Boes E, et al. Modifying effect of a common polymorphism in the interleukin-6 promoter on the relationship between long-term exposure to traffic-related particulate matter and heart rate variability. PLoS One 2014; 9: e104978.

92 Künzli N, Jerrett M, Mack WJ, et al. Ambient air pollution and atherosclerosis in Los Angeles. Environ Health Perspect 2005; 113: 201-206.

93 Perez L, Wolf K, Hennig F, et al. Air pollution and atherosclerosis: a cross-sectional analysis of four European cohort studies in the ESCAPE study. Environ Health Perspect 2015; 123: 597-605.

94 Provost EB, Madhloum N, Int Panis L, et al. Carotid intima-media thickness, a marker of subclinical atherosclerosis, and particulate air pollution exposure: the meta-analytical evidence. PLoS One 2015; 10: e0127014

95 Lorenz MW, Polak JF, Kavousi M, et al. Carotid intima-media thickness progression to predict cardiovascular events in the general population (the PROG-IMT collaborative project): a meta-analysis of individual participant data. Lancet 2012; 379: 2053-2062.

96 Newman JD, Thurston GD, Cromar K, et al. Particulate air pollution and carotid artery stenosis. J Am Coll Cardiol 2015; 65: 1150-1151.

97 Krishnan RM, Adar SD, Szpiro AA, et al. Vascular responses to long- and short-term exposure to fine particulate matter: MESA Air (Multi-Ethnic Study of Atherosclerosis and Air Pollution). J Am Coll Cardiol 2012; 60: 2158-2166.

98 Wilker EH, Ljungman PL, Rice MB, et al. Relation of long-term exposure to air pollution to brachial artery flow-mediated dilation and reactive hyperemia. Am J Cardiol 2014; 113: 2057-2063.

99 Langrish JP, Unosson J, Bosson J, et al. Altered nitric oxide bioavailability contributes to diesel exhaust inhalation-induced cardiovascular dysfunction in man. J Am Heart Assoc 2013; 2: e004309.

100 Vita JA. Endothelial function. Circulation 2011; 124: E906-E912.

101 Eze IC, Hemkens LG, Bucher HC, et al. Association between ambient air pollution and diabetes mellitus in Europe and North America: systematic review and meta-analysis. Environ Health Perspect 2015; 123: 381-389.

102 Rajagopalan S, Brook RD. Air pollution and type 2 diabetes mechanistic insights. Diabetes 2012; 61: 3037-3045.

103 Brook RD, Sun Z, Brook JR, et al. Extreme air pollution conditions adversely affect blood pressure and insulin resistance: the Air Pollution and Cardiometabolic Disease study. Hypertension 2016; 67: 77-85.

104 Thiering E, Heinrich J. Epidemiology of air pollution and diabetes. Trends Endocrinol Metab 2015; 26: 384-394

105 Rao X, Patel P, Puett R, et al. Air pollution as a risk factor for type 2 diabetes. Toxicol Sci 2015; 143: 231-241.

106 Markevych I, Wolf K, Hampel R, et al. Air pollution and liver enzymes. Epidemiology 2013; 24 : 934-935.

107 Beyerlein A, Krasmann M, Thiering E, et al. Ambient air pollution and early manifestation of type 1 diabetes. Epidemiology 2015; 26: E31-E32.

108 Malmqvist E, Larsson HE, Jönsson I, et al. Maternal exposure to air pollution and type 1 diabetes - accounting for genetic factors. Environ Res 2015; 140: 268-274.

109 Bollati V, Baccarelli A. Environmental epigenetics. Heredity 2010; 105: 105-112.

110 Kannan S, Misra DP, Dvonch JT, et al. Exposures to airborne particulate matter and adverse perinatal outcomes: a biologically plausible mechanistic framework for exploring potential effect modification by nutrition. Environ Health Perspect 2006; 114: 1636-1642.

111 van den Hooven EH, Pierik FH, de Kluizenaar Y, et al. Air pollution exposure and markers of placental growth and function: the generation R study. Environ Health Perspect 2012; 120: 1753-1759. 
Backes CH, Nelin T, Gorr MW, et al. Early life exposure to air pollution: how bad is it? Toxicol Lett 2013; 216: 47-53. Gauderman WJ, Avol E, Gilliland F, et al. The effect of air pollution on lung development from 10 to 18 years of age. N Engl J Med 2004; 351: 1057-1067.

Gauderman WJ, Vora H, McConnell R, et al. Effect of exposure to traffic on lung development from 10 to 18 years of age: a cohort study. Lancet 2007; 369: 571-577.

Stieb DM, Chen L, Eshoul M, et al. Ambient air pollution, birth weight and preterm birth: a systematic review and meta-analysis. Environ Res 2012; 117: 100-111.

Pedersen M, Giorgis-Allemand L, Bernard C, et al. Ambient air pollution and low birthweight: a European cohort study (ESCAPE). Lancet Respir Med 2013; 1: 695-704.

Dadvand P, Figueras F, Basagaña X, et al. Ambient air pollution and preeclampsia: a spatiotemporal analysis. Environ Health Perspect 2013; 121: 1365-1371.

Visentin S, Grumolato F, Nardelli GB, et al. Early origins of adult disease: low birth weight and vascular remodeling. Atherosclerosis 2014; 237: 391-399.

Abitbol CL, Rodriguez MM. The long-term renal and cardiovascular consequences of prematurity. Nat Rev Nephrol 2012; 8: 265-274.

Pike K, Pillow JJ, Lucas JS. Long term respiratory consequences of intrauterine growth restriction. Semin Fetal Neonatal Med 2012; 17: 92-98.

McIntire DD, Bloom SL, Casey BM, et al. Birth weight in relation to morbidity and mortality among newborn infants. N Engl J Med 1999; 340: 1234-1238.

Parker JD, Mendola P, Woodruff TJ. Preterm birth after the Utah Valley Steel Mill closure: a natural experiment. Epidemiology 2008; 19: 820-823.

Rich DQ, Liu K, Zhang J, et al. Differences in birth weight associated with the 2008 Beijing Olympics air pollution reduction: results from a natural experiment. Environ Health Perspect 2015; 123: 880-887.

176: 308-316.

Green R, Sarovar V, Malig B, et al. Association of stillbirth with ambient air pollution in a California cohort study. Am J Epidemiol 2015; 181: 874-882.

Hwang B-F, Lee YL, Jaakkola JJK. Air pollution and stillbirth: a population-based case-control study in Taiwan. Environ Health Perspect 2011; 119: 1345-1349.

Pearce MS, Glinianaia SV, Rankin J, et al. No association between ambient particulate matter exposure during pregnancy and stillbirth risk in the north of England, 1962-1992. Environ Res 2010; 110: 118-122.

Padula AM, Tager IB, Carmichael SL, et al. The association of ambient air pollution and traffic exposures with selected congenital anomalies in the San Joaquin Valley of California. Am J Epidemiol 2013; 177: 1074-1085.

Chen EK-C, Zmirou-Navier D, Padilla C, et al. Effects of air pollution on the risk of congenital anomalies: a systematic review and meta-analysis. Int J Environ Res Public Health 2014; 11: 7642-7668.

Schembari A, Nieuwenhuijsen MJ, Salvador J, et al. Traffic-related air pollution and congenital anomalies in Barcelona. Environ Health Perspect 2014; 122: 317-323.

Block ML, Calderón-Garcidueñas L. Air pollution: mechanisms of neuroinflammation and CNS disease. Trends Neurosci 2009; 32: 506-516.

Block ML, Elder A, Auten RL, et al. The outdoor air pollution and brain health workshop. Neurotoxicology 2012 33: 972-984.

Grandjean P, Landrigan PJ. Neurobehavioural effects of developmental toxicity. Lancet Neurol 2014; 13: 330-338. Brauer M. Air pollution, stroke, and anxiety. BMJ 2015; 350: h1510.

Ailshire JA, Crimmins EM. Fine particulate matter air pollution and cognitive function among older US adults. Am J Epidemiol 2014; 180: 359-366.

Weuve J, Puett RC, Schwartz J, et al.
Arch Intern Med 2012; 172: 219-227.

Ritz B, Lee PC, Hansen J, et al. Traffic-related air pollution and Parkinson's disease in Denmark: a case-control study. Environ Health Perspect 2016; 124: 351-356.

Kioumourtzoglou MA, Schwartz JD, Weisskopf MG, et al. Long-term PM2.5 exposure and neurological hospital admissions in the northeastern United States. Environ Health Perspect 2016; 124: 23-29.

Palacios N, Fitzgerald KC, Hart JE, et al. Particulate matter and risk of Parkinson disease in a large prospective study of women. Environ Health 2014; 13: 80.

Calderón-Garcidueñas L, Solt AC, Henríquez-Roldán C, et al. Long-term air pollution exposure is associated with neuroinflammation, an altered innate immune response, disruption of the blood-brain barrier, ultrafine particulate deposition, and accumulation of amyloid $\beta-42$ and $\alpha$-synuclein in children and young adults. Toxicol Pathol 2008; 36: 289-310.

41 Morgan TE, Davis DA, Iwata N, et al. Glutamatergic neurons in rodent models respond to nanoscale particulate urban air pollutants in vivo and in vitro. Environ Health Perspect 2011; 119: 1003-1009.

O’Brien JT. Vascular cognitive impairment. Am J Geriatr Psychiatry 2006; 14: 724-733. 111-140.

Suglia SF, Gryparis A, Wright RO, et al. Association of black carbon with cognition among children in a prospective birth cohort study. Am J Epidemiol 2008; 167: 280-286.

Perera FP, Li ZG, Whyatt R, et al. Prenatal airborne polycyclic aromatic hydrocarbon exposure and child IQ at age 5 years. Pediatrics 2009; 124: E195-E202.

Guxens M, Aguilera I, Ballester F, et al. Prenatal exposure to residential air pollution and infant mental development: modulation by antioxidants and detoxification factors. Environ Health Perspect 2012; 120: 144-149. Harris MH, Gold DR, Rifas-Shiman SL, et al. Prenatal and childhood traffic-related pollution exposure and childhood cognition in the Project Viva cohort (Massachusetts, USA). Environ Health Perspect 2015; 123: 1072-1078.

Sunyer J, Esnaola M, Alvarez-Pedrerol M, et al. Association between traffic-related air pollution in schools and cognitive development in primary school children: a prospective cohort study. PLoS Med 2015; 12: e1001792.

Kalkbrenner AE, Daniels JL, Chen JC, et al. Perinatal exposure to hazardous air pollutants and autism spectrum disorders at age 8. Epidemiology 2010; 21: 631-641. 
150 Volk HE, Lurmann F, Penfold B, et al. Traffic-related air pollution, particulate matter, and autism. JAMA Psychiatry 2013; 70: 71-77.

151 Raz R, Roberts AL, Lyall K, et al. Autism spectrum disorder and particulate matter air pollution before, during, and after pregnancy: a nested case-control analysis within the Nurses' Health Study II cohort. Environ Health Perspect 2015; 123: 264-270.

152 Wang Y, Eliot MN, Koutrakis P, et al. Ambient air pollution and depressive symptoms in older adults: results from the MOBILIZE Boston study. Environ Health Perspect 2014; 122: 553-558.

153 Bakian AV, Huber RS, Coon H, et al. Acute Air Pollution Exposure and Risk of Suicide Completion. Am J Epidemiol 2015; 181: 295-303.

154 Power MC, Kioumourtzoglou MA, Hart JE, et al. The relation between past exposure to fine particulate air pollution and prevalent anxiety: observational cohort study. BMJ 2015; 350: h1111.

155 Peterson BS, Rauh VA, Bansal R, et al. Effects of prenatal exposure to air pollutants (polycyclic aromatic hydrocarbons) on the development of brain white matter, cognition, and behavior in later childhood. JAMA Psychiatry 2015; 72: 531-540.

156 Wilker EH, Preis SR, Beiser AS, et al. Long-term exposure to fine particulate matter, residential proximity to major roads and measures of brain structure. Stroke 2015; 46: 1161-1166. 